\title{
Dematerialization, Decoupling, and Productivity Change
}

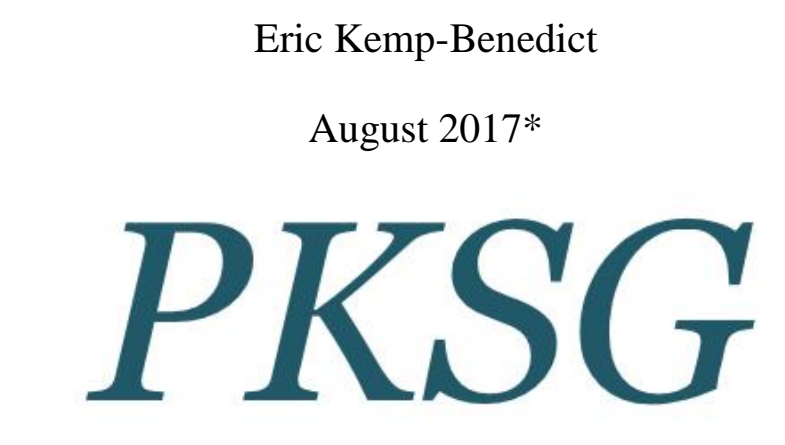

\section{Post Keynesian Economics Study Group}

Working Paper 1709

This paper may be downloaded free of charge from www.postkeynesian.net

(C) Eric Kemp-Benedict

Users may download and/or print one copy to facilitate their private study or for non-commercial research and may forward the link to others for similar purposes. Users may not engage in further distribution of this material or use it for any profit-making activities or any other form of commercial gain.

*This paper was updated in May 2018 


\title{
Dematerialization, Decoupling, and Productivity Change
}

\begin{abstract}
The prospects for long-term sustainability depend on whether, and how much, we can absolutely decouple economic output from total energy and material throughput. While relative decoupling has occurred - that is, resource use has grown less quickly than the economy - absolute decoupling has not, raising the question whether it is possible. This paper proposes a novel explanation for why decoupling has not happened historically, drawing on a recent theory of cost-share induced productivity change and an extension of post-Keynesian pricing theory to natural resources. Cost-share induced productivity change and pricing behavior set up two halves of a dynamic, which we explore from a post-Keynesian perspective. In this dynamic, resource costs as a share of GDP move towards a stable level, at which the growth rate of resource productivity is typically less than the growth rate of GDP. This provides a parsimonious explanation of the prevalence of relative over absolute decoupling. The paper then presents some illustrative applications of the theory.
\end{abstract}

Keywords: decoupling; dematerialization; cost-share induced technological change

JEL classifications: E12, O31, O33, Q32

Acknowledgements: The author would like to thank Peter Erickson, Sivan Kartha, Juan Antonio Montecino, and three anonymous reviewers for helpful comments at different stages of the writing. The work presented in this paper was funded in part by the Swedish International Development Cooperation Agency (Sida).

Eric Kemp-Benedict

Stockholm Environment Institute, 11 Curtis Avenue, Somerville, MA, USA 02144, email: eric.kempbenedict@sei.org 


\section{Introduction}

When the UN General Assembly (2015) adopted the 2030 Agenda for Sustainable Development, it brought a renewed focus to a long-standing question: the potential for material and energy throughput to decouple absolutely from economic growth. Goal 12 is to "Ensure sustainable consumption and production patterns," including "the sustainable management and efficient use of natural resources" by 2030 , while Goal 13 is to "Take urgent action to combat climate change and its impacts." As climate mitigation requires that most remaining fossil resources remain in the ground (McGlade and Ekins 2015), taking urgent action implies an immediate decoupling of fossil energy consumption from economic output. Recently, carbon emissions from fossil fuel use and industry have slowed, or even briefly reversed, indicating some success toward this goal, although not at a rate fast enough to meet globally-agreed climate targets (UNEP 2016). However, the wealth of nations depends on energy flows (Hall and Klitgaard 2012), and total energy and material use has not absolutely decoupled from GDP. Rather, we have seen relative decoupling, in which material and energy intensity declines at a slower rate than GDP grows, while absolute resource and energy consumption continue to rise (Bernardini and Galli 1993; Ayres and Warr 2009). This pattern seems likely to continue in future (Ward et al. 2016).

The substantial literature on dematerialization and decoupling has not reached consensus on mechanisms. Two persistent and partially competing concepts are Jevons' paradox (Jevons 1865; Khazzoom 1980; Alcott 2005; Sorrell 2009) and the Environmental Kuznets Curve (EKC) hypothesis (Auty 1985; Dinda 2004). Jevons' paradox states that an increase in resource efficiency leads indirectly to an absolute increase in the use of that resource, as a falling price brings formerly unprofitable resource-consuming processes into production and rising incomes drive consumption. The EKC hypothesis is motivated by a narrative of economic development. Early in the process, resource-intensive industrial production dominates, and raising incomes is more important than protecting the environment. As labor productivity and wages grow, industry declines relative to services, while environmental quality becomes more important than rapid growth. Ayres and van den Bergh (2005), Warr and Ayres (2012), and Cogoy (2004) extrapolate this dynamic, arguing that decoupling can occur through value-creation in the service sector as rising demand for services relative to physical goods is reinforced by increasing service sector labor productivity through human capital accumulation.

Jevons' paradox suggests that decoupling will never happen, while the EKC hypothesis suggests that decoupling can occur after a sufficiently long period. Both are contested. For Jevons' paradox, in particular, a number of papers argue both for and against the hypothesis as it applies to mature economies (e.g., Sorrell 2009; Cullenward and Koomey 2016). The evolving empirical literature on the EKC appears to disprove its existence (Stern 2004; Wagner 2008), but the concept is attractive enough for discussion to continue (Dinda 2004; Kijima, Nishide, and Ohyama 2010). We do not address the controversies in this paper, but note that proponents of Jevons' paradox and of the EKC propose distinct causal relationships between energy and material use on long-run GDP growth. Jevons' paradox assumes that resources constrain growth, so releasing those constraints stimulates expansion, while the EKC hypothesis assumes that economic growth drives resource use, with a relationship that depends on the developmental stage of the economy. 
The phenomenon of relative decoupling is related to the concept of the economy-wide or macroeconomic rebound effect (Thomas and Azevedo 2013). Rebound is concerned with the unintended consequences of efficiency gains. It is often applied to household demand (as in Azevedo 2014), but also encompasses efficiency gains by industry, as we consider in this paper. Both Dimitropoulos (2007) and Cullenward and Koomey $(2016,204)$ argue that the theoretical and empirical bases of the economy-wide rebound effect are weak, lacking specific causal mechanisms. The main theoretical approaches apply neoclassical production functions (notably Saunders 1992) or computable general equilibrium (CGE) models. Results from these studies are sharply conflicting.

In this paper we provide a parsimonious explanation, different than existing explanations, for the failure of resource throughput to decouple absolutely from economic output, which we explore from a post-Keynesian perspective. We start from two assumptions: 1) innovation that saves on inputs to the production of goods and services is biased toward higher-cost inputs, as measured by the cost share; and 2) resource prices rise in the short run when demand increases relative to capacity, while manufacturing prices are administered (Lee 1999). These two assumptions set up two halves of a process, which can be thought of as a supply-demand dynamic that plays out over time. Firms buy resources on commodity markets at prevailing and publicly-announced prices. Those prices clear their markets in a short period during which firms' production schedules determine an inelastic level of demand. Demand for resources responds to price changes indirectly, and after a delay, as firms reduce costs at prevailing prices through technological innovation, and then adjust their administered prices to reflect their revised cost structure. Industrial firms pay very little attention to demand when setting prices (Coutts and Norman 2013), so their prices are not market-clearing; in this post-Keynesian model, it is productivity growth rates and cost shares, rather than prices, that adjust to move the system toward an equilibrium.

The assumption that resource productivity growth is driven by resource costs is an extension to natural resources of theories of cost-share induced technological change, in which the relative pace of labor-saving or capital-saving innovation increases with the shares of labor and capital costs in production (Hicks 1932, 124 ff.; Duménil and Lévy 1995; Foley 2003a, 42 ff., 2003b; Kemp-Benedict 2017). This can be contrasted with neoclassical theories of induced technological change, in which profit-maximizing firms choose technologies within a space of possibilities that is bounded by an expanding production possibilities frontier (Kumar and Managi 2009; Acemoglu 1998, 2002). The approach to cost-share induced technological change followed in this paper, and described in detail in Kemp-Benedict (2017), does not require a production possibilities frontier. Instead, consistent with evolutionary theories of technological change (Nelson and Winter 1982; Duménil and Lévy 1995), firms seek marginal improvements on existing technology, and adopt discoveries that increase profits at prevailing prices. The result from Kemp-Benedict is quite general: the Jacobian matrix expressing the change in productivity growth rates with respect to cost shares is symmetric and, to a good approximation, positive semi-definite. These characteristics permit a stability analysis with very few additional assumptions.

In post-Keynesian theory most firms operate in an oligopolistic environment and have considerable flexibility in setting prices, including wages. Prices are cost-based, largely insensitive to demand, and maintained across pricing periods that can be several quarters long (Coutts and Norman 2013). The price system is determined by the costs of inputs, inter-industry relationships, and profit margins, 
which are set high enough to maintain the enterprise as a going concern but not so high as to encourage entry by rivals. Firms tend to engage in non-price competition because price wars, in which firms seek to undercut each other, are costly to all participants. Markets in natural resources are different, because they are commodities, so one producer's output is indistinguishable from that of any other. Thus, even in oligopolistic industries, producers are not free to set their prices because they cannot engage in non-price competition. Commodities are graded, bundled and sold on exchanges, where prices respond to changes in demand relative to storage and to local supply conditions (Gray and Rutledge 1971; Williams 1986). While the post-Keynesian literature recognizes that resources are priced differently than other goods (Kalecki 1969, 11; Kriesler 1988; Coutts and Norman 2013, 8), that distinction is rarely taken into account in post-Keynesian models. We therefore devote a section of the paper to resource pricing. We apply conventional post-Keynesian pricing in the productive sector and resource pricing in extractive sectors.

We present the theoretical arguments in terms of a two-sector model, consisting of an extractive and a productive sector. While keeping the fossil extractive industry in mind throughout the analysis, we refer to a generic "resource". Addressing resource costs in the productive sector separately from labor and profits, we show that resource costs as a share of GDP (the "resource share") and resource productivity growth rates move towards stable levels, at which the growth rate of resource productivity is nearly always less than the growth rate of GDP. That is, we find relative but not absolute decoupling arising from the behavioral assumptions of the model. We then show that the same result holds when labor costs and profits are included. The model has an equilibrium defined in terms of cost shares and productivity growth rates rather than prices.

The main novelty of this paper is its explanation of decoupling, or the lack of it, using a recent innovation in the theory of cost-share induced technological change (Kemp-Benedict 2017). We identify general economic behaviors that can underlie both relative and absolute decoupling in different environments. We show that when resources are comparatively abundant, relative decoupling should occur, while absolute decoupling should not, although transitory deviations are possible during technological or structural transitions. Thus, with few assumptions, the model explains the dominant pattern of resource use observed in high-income countries, helping to fill gaps in the theory of decoupling and the related concept of the macroeconomic rebound effect. As we seek to describe generic outcomes from a minimal set of assumptions, the paper is necessarily theoretical, but to make the ideas more concrete we show how the theory can be applied in practice.

\section{Extractive industries and commodity prices}

Post-Keynesian pricing theory is well developed for the manufacturing sector (Coutts and Norman 2013). It accounts for the oligopolistic nature of most industries, the need to plan for a fundamentally uncertain future, and, most importantly, the pricing strategies and procedures actually used in firms. Post-Keynesian firms have considerable freedom to set their prices in order to meet target profit rates, constrained mainly by their desire to discourage their rivals from emulating their successes. The theory is less well developed for natural resources such as mining, oil, coal, and natural gas. While fossil fuel industries are oligopolistic, they are not as free as manufacturing firms to set their prices, because they produce interchangeable commodities for a global market. Prices for commodities are set in markets for contracts of different maturities, including for immediate delivery (spot prices). 
Spot prices for oil and gas are reported for benchmark commodities or at the port of Rotterdam, while futures contracts are traded on exchanges. For example, Brent crude is a benchmark light (lowdensity) and sweet (low-sulfur) crude oil, as is West Texas Intermediate (WTI). Large producers manage price fluctuations by starting up or shutting down wells with different operating costs depending on the current price.

An abundant literature on commodity markets seeks to understand differences between spot and futures prices and the economic role of futures markets (for reviews, see Gray and Rutledge 1971; Kamara 1982; Carter 1999). In this paper we abstract from these details, while drawing on the "cost of storage" theory of commodity prices initiated by Working $(1948,1949)$, particularly in the form put forward by Williams (1986). The effective cost of storage may be negative, due to Kaldor's (1939) "convenience yield", or the value of having stocks on hand to meet demand for immediate delivery. Keynes' own theory of "normal backwardation"1, which argues that the spread between spot and futures prices reflects a risk premium, does not perform as well (Fama and French 1987; Carter 1999). Yet another theory (Higinbotham 1976) argues that the apparently negative cost of storage is an illusion. Using a rational actor model, this theory argues that if stocks are ever zero due to a general shortage, the price can rise as high as the market will bear, while futures prices reflect a return to normal conditions. Assuming that all stocks of a storable commodity may sometimes fall to zero, the spot price will normally be above the futures price. However, as Williams (1986, 33-34) points out, total stocks for major commodities have historically never been zero. An individual facility may exhaust its stocks, but there is never a case where the commodity is unavailable anywhere. Instead, the spot price rises when stocks are low, in line with Kaldor's convenience yield concept.

The special characteristics of extractive industries can be seen in World Bank data on resource rents ${ }^{2}$. The World Bank estimates rents by subtracting production costs from the world spot price (World Bank 2011). That is, it computes rents as the profits of the extractive sector. Figure 1 shows oil and gas rents as a percentage of GDP for the United States from 1970 to 2015. Sudden and unexpected changes in supply conditions affect prices; the oil crises of 1973 and 1979 are clearly visible in the graph, as are the smaller increases in the first and second Gulf Wars. Sudden changes in demand also affect prices, as illustrated by the fall in rents after the financial crisis. Yet, extractive firms must cover their costs in the long run, and they try to do so. Since 2001 there has been a trend increase in oil prices (interrupted by a fall after the 2007 financial crisis), but the trend is barely visible in the rents. This is consistent with prices that remain close to extractive firms' target markup applied to costs that are rising due to falling energy return on energy investment (EROI) (Murphy and Hall 2011). The recent experience of the natural gas sector shows that firms do not always succeed in meeting their target profit rate, as expanding low-cost supply through hydraulic fracturing (fracking) led to falling prices and unusually low rents for incumbent firms with higher operating costs.

\section{FIGURE 1 NEAR HERE}

\footnotetext{
${ }^{1}$ Backwardation means futures prices are lower than the spot price, while the opposite case is called "contango".

${ }^{2}$ World Development Indicators, accessed 24 November 2017.
} 
For the model developed below, we assume a single aggregate resource, with a price $p_{r}$ per unit (for example, per MJ or $\mathrm{kg}$ ). The price tends to rise with unit production costs $c_{r}$, but as the resource is an actively traded commodity, its price also depends on total resource demand $R_{\text {tot }}$ relative to capacity $C$,

$$
p_{r}=c_{r} \mu_{r}\left(\frac{R_{\mathrm{tot}}}{C}\right), \quad \mu_{r}^{\prime}>0
$$

For a storable resource with variable yield, such as an agricultural commodity, capacity would reflect a combination of past and expected yields, as well as stocks. When yields are more predictable, as for crude oil, or storage is particularly costly, as for electricity, the capacity might be closer to installed production capacity. When capacity is sufficient to meet demand, the function $\mu_{r}$ is equal to extractive firms' desired markup. When demand rises relative to capacity, the price rises and firms enjoy exceptional profits. Conversely, when demand falls or there is overcapacity, profits fall. Expanding capacity and changing the resource demands of firms each take time, which accounts for the persistence of high and low rents in Figure 1.

While we focus on fossil fuels, equation (1) should be suitable for commodities in general, at least in aggregated and stylized models like the one presented in this paper, which abstract from differences between spot and future prices and between spot prices at different locations. Those differences are the focus of considerable theoretical and empirical research, as they are the source of income for speculators in commodities markets. They arise for similar reasons for different storable commodities - different local supply conditions, the overall level of stock, whether further processing needs to be done, and how accessible the commodity is, e.g., already available on a train, bunker, or receiver's tank or still in the warehouse or supplier's tanks - but the specifics vary considerably from one commodity to another.

The non-wage operating costs of fossil fuel industries are typically high, so wages as a share of value added are smaller than in other sectors. Figure 2 illustrates this with data from the US Bureau of Economic Analysis. When oil rents have fallen, as in 1998, 2009 and 2015, the drop has mostly been absorbed by profits, while the wage share has risen. Thus, while wage income is not a trivial component of expenditure in extractive industries, it is not large and varies less than profits, as captured in the World Bank's estimates for resource rents (shown in Figure 1). It is also a very small proportion of total wage income in large and diversified economies such as the US. In the model, we make the simplifying assumption that wages in the extractive sector can be neglected and focus on other costs.

\section{FIGURE 2 NEAR HERE}

Some of the extractive sector's costs are for the resource itself, such as energy used to extract energy resources (analogous to the seed used to produce grain in a classical model). Other costs are for intermediate goods purchased from the rest of the economy. Total unit costs can thus be written

$$
c_{r}=a_{p}+a_{r} p_{r}
$$

where $a_{p}$ is a technical coefficient for the non-resource (productive) sector, $a_{r}$ is own use in the resource sector, and all prices are expressed relative to the price of goods in the productive sector, which is the numéraire. 
The coefficient $a_{r}$ can fall when efficiency gains are possible, but is generally expected to rise as more accessible resources are exhausted. It is similar to EROI, but includes only resources used for operating equipment, and not the resources used to build and install that equipment. It is more directly related to the net external power ratio (NEPR) (King, Maxwell, and Donovan 2015), which is defined as the net production of energy per unit of energy used for operation. Denoting NEPR by $n$, the relationship is

$$
a_{r}=\frac{1}{1+n} .
$$

We expect NEPR to fall (and $a_{r}$ to rise) over time as producers move to sources that are progressively harder to extract. As shown in King et al. (2015), NEPR has fallen for the world as a whole, while energy exporters - those with large and low-cost sources - tend to have high values for NEPR. However, the trend is not monolithic, and is affected by technological improvements and shifts between resources (e.g., from coal to oil to natural gas and tar sands). For example, while NEPR has fallen in Saudi Arabia, in Norway it has risen, while in the UK it fell between 1960 and 1970; rose between 1970 and 1980; stayed roughly constant through 2000; and then fell again (King, Maxwell, and Donovan 2015 Supplementary File 2).

Substituting equation (2) into equation (1) and solving for the resource price, $p_{r}$, gives

$$
p_{r}=\frac{a_{p} \mu_{r}\left(R_{\mathrm{tot}} / C\right)}{1-a_{r} \mu_{r}\left(R_{\mathrm{tot}} / C\right)} .
$$

Because $\mu_{r}$ is an increasing function of $R_{\mathrm{tot}} / C$, so is the resource price. Also, because $a_{r}$ changes over time, and is expected to increase in the long run, the real resource price shares these properties. In principle, the coefficient $a_{p}$ can also change, but cannot be zero: every extractive activity requires some goods from outside the sector. We expect it to increase with increasing difficulty of accessing resources $-e . g$., servicing deep-sea drilling rigs is costlier than servicing rigs on land. Thus, $a_{p}$ is expected to generally rise and fall with $a_{r}$.

We note that the right-hand side of equation (4) diverges as its denominator approaches zero. A condition for economic sustainability is therefore that

$$
a_{r}=\frac{1}{\mu_{r}} .
$$

Put in terms of NEPR using equation (3), this implies a constraint

$$
n ? \mu_{r}-1
$$

This is a generous condition. For a 20\% markup (or a profit margin of 1.2), NEPR must substantially exceed 0.2. But NEPR estimates generally exceed 10 (King, Maxwell, and Donovan 2015 Supplementary File 2). Moreover, the constraint in equation (6) is less binding than the minimum EROI of three estimated by Hall et al. (2009) as necessary to sustain civilization. 


\section{Introducing a two-sector model}

In this section we present a two-sector model with an extractive and a productive sector. The analytical focus is on the productive sector, while the extractive sector plays a passive role. Real output from the productive sector is $Y$ (gross of intermediate inputs from the resource sector, but net of any output used as an intermediate input by the sector itself) and it has a resource productivity $v$. Productive-sector resource use $R$ is then given by

$$
R=\frac{Y}{v} .
$$

Total resource use, $R_{\mathrm{tot}}$, which appears in equation (4), includes both the quantity demanded by the productive sector and the amount needed by the extractive sector,

$$
R_{\mathrm{tot}}=R+a_{r} R_{\mathrm{tot}} \Rightarrow R_{\mathrm{tot}}=\frac{R}{1-a_{r}} .
$$

The resource share (resource costs as a share of the value of output) in the productive sector is

$$
\rho=\frac{p_{r}}{v}
$$

Productive sector value added, $V_{p}$, is given by the value of output net of resource costs,

$$
V_{p}=Y-p_{r} R
$$

while extractive sector value added, $V_{r}$, is the value of output net of own use and payments to the productive sector,

$$
V_{r}=p_{r} R_{\mathrm{tot}}-p_{r} a_{r} R_{\mathrm{tot}}-a_{p} R_{\mathrm{tot}}=p_{r} R-\frac{a_{p}}{1-a_{r}} R
$$

The sum of these is GDP, $G$,

$$
G=V_{p}+V_{r}=\left(1-\frac{1}{v} \frac{a_{p}}{1-a_{r}}\right) Y .
$$

Total profits and resource rents, $\Pi$, are given by GDP less labor costs in the productive sector, as we are neglecting labor costs in the extractive sector. We keep track of cost shares in the productive sector for wages, profits, and intermediate expenditure on resources. Denoting the wage share in the productive sector by $\omega$, profits are equal to ${ }^{3}$,

$$
\Pi=G-\omega Y=\left(1-\frac{1}{v} \frac{a_{p}}{1-a_{r}}-\omega\right) Y .
$$

\footnotetext{
${ }^{3}$ The wage share of GDP, $\omega_{G}$, is the wage bill $\omega Y$ divided by $G, \omega_{G}=\omega Y / G$.
} 
We return to total GDP later in this section when we discuss decoupling, but in the analysis we focus on decisions made within the productive sector. The relevant output is $Y$ and the cost shares are the productive sector wage share $\omega$, resource share $\rho$, and profit share $\pi$, which sum to one,

$$
1=\omega+\pi+\rho .
$$

Using the expression for the real resource price in equation (4), we can relate the growth rate of resource productivity to the growth rate of the price. Put in terms of resource use in the productive sector rather than total resource use, we can write equation (4) as

$$
p_{r}=\frac{a_{p} \mu_{r}}{1-a_{r} \mu_{r}} \equiv F\left(\frac{R}{C}, t\right), \quad \mu_{r}=\mu_{r}\left(\frac{1}{1-a_{r}} \frac{R}{C}\right), \quad \mu_{r}^{\prime}>0 .
$$

In this equation we have defined the expression for the real resource price as a function $F$ of $R / C$ and time $t$. If we assume that $a_{p}$ rises and falls with $a_{r}$, then $F$ has the following properties: 1 ) it rises or falls over time as $a_{r}$ rises or falls (or as NEPR falls or rises); 2 ) it is an increasing function of $R / C$. We denote exogenous growth in $F$ by $\beta$ and the elasticity of $F$ with respect to its first argument by $\varepsilon$,

$$
\beta \equiv \frac{1}{F} \frac{\partial F}{\partial t}, \quad \varepsilon \equiv \frac{R}{C} \frac{F^{\prime}}{F}
$$

The growth rate of the price is then given by

$$
\hat{p}_{r}=\beta+\varepsilon(\hat{R}-\hat{C})
$$

The term $\beta$ is an exogenous vertical shift in the supply price schedule. From equation (15) we associate this with increasing (or, possibly, decreasing) difficulty of extraction, moderated but perhaps not fully offset by efficiency improvements. However, we abstract from the details and simply specify $\beta$ exogenously. The final term is the local elasticity of the price with respect to resource capacity utilization, $\varepsilon$, multiplied by the growth rate of $R / C ; \varepsilon$ is non-negative. Both $\varepsilon$ and $\beta$ depend on the ratio of resource extraction to capacity, $R / C$, and, if $\beta$ is nonzero, on the time $t$.

From equation (9), we find that the growth rate of the productive sector resource share is equal to

$$
\hat{\rho}=\hat{p}_{r}-\hat{v} .
$$

Combining this with equation (17), we have

$$
\hat{\rho}=\beta+\varepsilon(\hat{R}-\hat{C})-\hat{v}
$$

and substituting for $R$ using equation (7) gives

$$
\hat{\rho}=\beta+\varepsilon(\hat{Y}-\hat{C})-(1+\varepsilon) \hat{v} .
$$

This expresses the change in the resource share as a function of productive sector growth and resource productivity growth. It also allows for a possible exogenous shift in the resource supply schedule through $\beta$. Through its final term, this relationship provides one half of a supply-demand dynamic. 
The other half of the dynamic is given by cost-share induced technological change within the productive sector, in which the rate of resource productivity improvement increases with the resource cost share (Kemp-Benedict 2017),

$$
\frac{\Delta \hat{v}}{\Delta \rho}>0
$$

Suppose that the right-hand side of equation (20) is initially positive (a similar argument holds if it is negative). Then the resource share is increasing, which implies, from equation (21), that the pace of resource productivity improvement is also increasing. This induces a negative feedback in equation (20) that slows the growth in $\rho$. Due to the negative feedback, the resource share rises until it reaches a stable value at which the right-hand side of equation (20) is zero.

This system is not closed, because a changing productive sector resource cost share must be balanced by a change in the sector's profit or wage share, which will then induce further productivity changes. We introduce a fully closed model in the next section.

In this system, an equilibrium is characterized by a constant resource cost share. Setting the left-hand side of equation (20) to zero and solving for the resource productivity growth rate gives its equilibrium value,

$$
\hat{v}_{\text {eqm }}=\frac{\beta}{1+\varepsilon}+\frac{\varepsilon}{1+\varepsilon}(\hat{Y}-\hat{C})
$$

We next express this in terms of GDP, $G$, rather than output from the productive sector, $Y$. From equation (12), we find that

$$
\hat{G}=\left(1-\frac{1}{v} \frac{a_{p}}{1-a_{r}}\right)^{-1} \frac{d}{d t}\left(1-\frac{1}{v} \frac{a_{p}}{1-a_{r}}\right)+\hat{Y} \equiv \gamma+\hat{Y} .
$$

The sign of $\gamma$ is ambiguous, but some cases can be distinguished. If resources are relatively abundant, so that $a_{r}$ and $a_{p}$ are stable, then the dominant factor determining the sign of $\gamma$ is productive sector resource productivity growth. Under these conditions, and with steady or growing resource productivity, $\gamma$ is positive or zero. If resources are constrained, rising $a_{r}$ and $a_{p}$ can offset the effect of rising productivity, perhaps enough to make $\gamma$ negative. However, a trend in that direction would ultimately be halted by stagnation (or collapse) or a change in the material basis of the economy; at the extreme, all resources and goods produced by the productive sector would be dedicated to extracting resources. For any given economic activity, rising resource productivity is ultimately constrained by thermodynamics, but in principle aggregate resource productivity can continue to rise through a structural shift away from resource-intensive sectors such as manufactures toward less resource-intensive sectors such as services.

Suppose that resources are comparatively abundant, so $\gamma \geq 0, \beta=0$, and $\varepsilon>0$, while growth in capacity is assumed not to exceed requirements. Under these conditions, at equilibrium we find the growth rate of resource productivity to be less than the growth rate of GDP,

$$
\hat{v}_{\text {eqm }}=\frac{\varepsilon}{1+\varepsilon}(\hat{G}-\gamma-\hat{C})<\hat{G}, \quad \beta=0, \gamma \geq 0 .
$$


This is the essential result: under the conditions of comparative resource abundance that have held in the past century, we expect relative but not absolute decoupling.

If $\beta$ is positive, then resource productivity can rise faster than GDP. Under a temporary increase in the resource price, from equation (16), $\beta$ will be positive for a time and then return to zero. From equation (20), this implies that $\rho$ will also grow. From equation (21), this will stimulate faster resource efficiency improvements, until a new equilibrium is established, at which equation (22) holds. While $\beta$ is positive, resource productivity can, for a time, rise faster than GDP. However, after the exogenous price rise, $\beta$ returns to zero and the equilibrium rate of increase in resource productivity falls below the growth rate of GDP. The net effect is a temporary jump in productivity growth, as was seen after the oil crises of the 1970s. It was a transient phenomenon that extended through the mid-1980s (cf. Ayres and Warr 2009, fig. 3.5f and 3.6).

\section{A closed model with two kinds of resource}

In this section we present a fully closed model. As before, we emphasize that equilibrium in this postKeynesian model is defined by constant cost shares and productivity growth rates in the productive sector, rather than prices. We maintain the notation for the wage and profit cost shares in the productive sector, $\omega$ and $\pi$, and introduce labor and capital productivities $\lambda$ and $\kappa$. We expand to two resources, non-renewable (NR) and renewable (R), with resource cost shares $\rho_{\mathrm{NR}}$ and $\rho_{\mathrm{R}}$, and productivities $v_{\mathrm{NR}}$ and $v_{\mathrm{R}}$. These cost shares and productivities apply to the productive sector alone, while changes in the extractive sector are specified exogenously.

In a model of cost-share induced technological change, productivity growth rates respond to cost shares. The strength of the response can change over time due to shifting technological potential due to new discoveries and exhaustion of opportunities opened by prior discoveries (Gordon 1999; Perez 2010). In this paper, we apply the particular theory of cost-share induced technological change proposed by Kemp-Benedict (2017). That theory makes quite general assumptions: technological discovery is random, with a probability distribution that does not depend on the cost shares (at least in the short run), and firms adopt innovations that raise their return to capital within a period in which prices can be assumed fixed. Under those assumptions, the Jacobian matrix of partial derivatives of the productivity growth rates with respect to cost shares is symmetric and (to a good approximation ${ }^{4}$ ) positive semi-definite. This result holds when the functional forms are expressed in terms of all cost shares, even though, as they must sum to one, they are not in fact independent. To make use of these convenient properties of the Jacobian matrix, we express productivity growth rates in terms of all cost shares at this point, and impose the condition that they sum to one later in the analysis. We have

$$
\begin{gathered}
\hat{\lambda}=\left(\omega, \pi, \rho_{\mathrm{R}}, \rho_{\mathrm{NR}}, t\right), \\
\hat{\kappa}=k\left(\omega, \pi, \rho_{\mathrm{R}}, \rho_{\mathrm{NR}}, t\right), \\
\hat{v}_{\mathrm{NR}}=r_{\mathrm{NR}}\left(\omega, \pi, \rho_{\mathrm{R}}, \rho_{\mathrm{NR}}, t\right),
\end{gathered}
$$

\footnotetext{
${ }^{4}$ In theory, firms know with certainty whether an innovation will raise their profits. The sharp cutoff makes the matrix semi-definite. In reality, they cannot be certain, so deviations might be observed.
} 


$$
\hat{v}_{\mathrm{R}}=r_{\mathrm{R}}\left(\omega, \pi, \rho_{\mathrm{R}}, \rho_{\mathrm{NR}}, t\right) .
$$

Using a subscript to indicate a partial derivative with respect to the argument, we can write the Jacobian matrix, $\mathbf{M}$, as

$$
\mathbf{M}=\left(\begin{array}{cccc}
\omega & \pi & \rho_{\mathrm{NR}} & \rho_{\mathrm{R}} \\
k_{\omega} & k_{\pi} & k_{\rho_{\mathrm{NR}}} & k_{\rho_{\mathrm{R}}} \\
r_{\mathrm{NR}, \omega} & r_{\mathrm{NR}, \pi} & r_{\mathrm{NR}, \rho_{\mathrm{NR}}} & r_{\mathrm{NR}, \rho_{\mathrm{R}}} \\
r_{\mathrm{R}, \omega} & r_{\mathrm{R}, \pi} & r_{\mathrm{R}, \rho_{\mathrm{NR}}} & r_{\mathrm{R}, \rho_{\mathrm{R}}}
\end{array}\right) .
$$

We assume non-renewable and renewable resources to be substitutable. That is not necessarily the case with current production systems, because, for example, non-renewable resources are used to produce biofuel crops. However, to anticipate a transition to a renewables-based economy and simplify the present analysis, we assume that they can be treated as substitutes. Using the symmetry properties of $\mathbf{M}$, we denote the cost-share induced substitution effect by $S$, where

$$
S=-r_{\mathrm{NR}, \rho_{\mathrm{R}}}=-r_{\mathrm{R}, \rho_{\mathrm{NR}}} .
$$

We denote the own-response for resource $i=\mathrm{NR}, \mathrm{R}$ by $Z_{i}$,

$$
Z_{\mathrm{NR}}=r_{\mathrm{NR}, \rho_{\mathrm{NR}}}, \quad Z_{\mathrm{R}}=r_{\mathrm{R}, \rho_{\mathrm{R}}} .
$$

From the positive semi-definiteness of $\mathbf{M}$, these must be non-negative. As we expect firms to respond to a change in cost shares, we assume them to be strictly positive.

We further assume capital and either type of resource to be complements, where the strength of that relationship for resource $i, K_{i}$, depends on whether non-renewable or renewable resources predominate in the economy. Using the symmetry property of $\mathbf{M}$, we have

$$
K_{\mathrm{NR}}=k_{\rho_{\mathrm{NR}}}=r_{\mathrm{NR}, \pi}, \quad K_{\mathrm{R}}=k_{\rho_{\mathrm{R}}}=r_{\mathrm{R}, \pi} .
$$

Finally, we assume labor to be substitutable with capital and either type of resource, and define the positive quantities

$$
L_{K}=-{ }_{\pi}=-k_{\omega}, \quad L_{\mathrm{NR}}=-\rho_{\mathrm{NR}}=-r_{\mathrm{NR}, \omega}, \quad L_{\mathrm{R}}=-\rho_{\mathrm{R}}=-r_{\mathrm{R}, \omega} .
$$

Using this notation, to first order in variation of the cost shares, we can write the change in the productivity growth rates as

$$
\begin{gathered}
\Delta \hat{\lambda}={ }_{\omega} \Delta \omega-L_{K} \Delta \pi-L_{\mathrm{NR}} \Delta \rho_{\mathrm{NR}}-L_{\mathrm{R}} \Delta \rho_{\mathrm{R}}+{ }_{t} \Delta t, \\
\Delta \hat{\kappa}=-L_{K} \Delta \omega+k_{\pi} \Delta \pi+K_{\mathrm{NR}} \Delta \rho_{\mathrm{NR}}+K_{\mathrm{R}} \Delta \rho_{\mathrm{R}}+k_{t} \Delta t, \\
\Delta \hat{v}_{\mathrm{NR}}=-L_{\mathrm{NR}} \Delta \omega+K_{\mathrm{NR}} \Delta \pi+Z_{\mathrm{NR}} \Delta \rho_{\mathrm{NR}}-S \Delta \rho_{\mathrm{R}}+r_{\mathrm{NR}, t} \Delta t, \\
\Delta \hat{v}_{\mathrm{R}}=-L_{\mathrm{R}} \Delta \omega+K_{\mathrm{R}} \Delta \pi-S \Delta \rho_{\mathrm{NR}}+Z_{\mathrm{R}} \Delta \rho_{\mathrm{R}}+r_{\mathrm{R}, t} \Delta t .
\end{gathered}
$$

At this point we impose the condition that cost share sum to one, so changes in cost shares sum to zero, 


$$
\Delta \omega=-\left(\Delta \pi+\Delta \rho_{\mathrm{NR}}+\Delta \rho_{\mathrm{R}}\right)
$$

Substituting into the expressions above,

$$
\begin{gathered}
\Delta \hat{\lambda}=-\left({ }_{\omega}+L_{K}\right) \Delta \pi-\left(\omega_{\omega}+L_{\mathrm{NR}}\right) \Delta \rho_{\mathrm{NR}}-\left(\omega_{\omega}+L_{\mathrm{R}}\right) \Delta \rho_{\mathrm{R}}+{ }_{t} \Delta t, \\
\Delta \hat{\kappa}=\left(k_{\pi}+L_{K}\right) \Delta \pi+\left(K_{\mathrm{NR}}+L_{K}\right) \Delta \rho_{\mathrm{NR}}+\left(K_{\mathrm{R}}+L_{K}\right) \Delta \rho_{\mathrm{R}}+k_{t} \Delta t, \\
\Delta \hat{v}_{\mathrm{NR}}=\left(K_{\mathrm{NR}}+L_{\mathrm{NR}}\right) \Delta \pi+\left(Z_{\mathrm{NR}}+L_{\mathrm{NR}}\right) \Delta \rho_{\mathrm{NR}}+\left(L_{\mathrm{NR}}-S\right) \Delta \rho_{\mathrm{R}}+r_{\mathrm{NR}, t} \Delta t, \\
\Delta \hat{v}_{\mathrm{R}}=\left(K_{\mathrm{R}}+L_{\mathrm{R}}\right) \Delta \pi+\left(L_{\mathrm{R}}-S\right) \Delta \rho_{\mathrm{NR}}+\left(Z_{\mathrm{R}}+L_{\mathrm{R}}\right) \Delta \rho_{\mathrm{R}}+r_{\mathrm{R}, t} \Delta t .
\end{gathered}
$$

From this point forward, we focus on the system defined by capital and resource productivity, with the corresponding profit and resource cost shares, and drop equation (39). We assume that firms in the productive sector adopt target-return pricing, which means that the profit rate $r$ (the product of $\pi$ and $\kappa)$ is maintained at a fixed value. That is, after prices are adjusted,

$$
\Delta r=\kappa \Delta \pi+\pi \Delta \kappa=0 .
$$

From this we see that

$$
\Delta \pi=-\pi \hat{\kappa}
$$

Assuming the same pricing behavior as before for resources, separately for non-renewable and renewable resources $i=\mathrm{NR}, \mathrm{R}$, we also have, from equation (20), that

$$
\Delta \rho_{i}=\rho_{i}\left[\beta_{i}+\varepsilon_{i}\left(\hat{Y}-\hat{C}_{i}\right)-\left(1+\varepsilon_{i}\right) \hat{v}_{i}\right]
$$

To simplify the notation in the following, we identify the first two terms in brackets as the external factors driving the resource price, and denote them $D_{i}$,

$$
D_{i} \equiv \beta_{i}+\varepsilon_{i}\left(\hat{Y}-\hat{C}_{i}\right) .
$$

Substituting into equations (40)-(42), we have the system

$$
\left(\begin{array}{c}
\Delta \hat{\kappa} \\
\Delta \hat{v}_{\mathrm{NR}} \\
\Delta \hat{v}_{\mathrm{R}}
\end{array}\right)=\mathbf{C} \cdot\left(\begin{array}{c}
\hat{\kappa} \\
\hat{v}_{\mathrm{NR}} \\
\hat{v}_{\mathrm{R}}
\end{array}\right)+\left(\begin{array}{c}
F_{K} \\
F_{\mathrm{NR}} \\
F_{\mathrm{R}}
\end{array}\right)
$$

where the matrix of coefficients of the productivity growth rates, $\mathbf{C}$, is given by

$$
\mathbf{C}=\left(\begin{array}{ccc}
-\left(k_{\pi}+L_{K}\right) \pi & -\left(K_{\mathrm{NR}}+L_{K}\right)\left(1+\varepsilon_{\mathrm{NR}}\right) \rho_{\mathrm{NR}} & -\left(K_{\mathrm{R}}+L_{K}\right)\left(1+\varepsilon_{\mathrm{R}}\right) \rho_{\mathrm{R}} \\
-\left(K_{\mathrm{NR}}+L_{\mathrm{NR}}\right) \pi & -\left(Z_{\mathrm{NR}}+L_{\mathrm{NR}}\right)\left(1+\varepsilon_{\mathrm{NR}}\right) \rho_{\mathrm{NR}} & -\left(L_{\mathrm{NR}}-S\right)\left(1+\varepsilon_{\mathrm{NR}}\right) \rho_{\mathrm{NR}} \\
-\left(K_{\mathrm{R}}+L_{\mathrm{R}}\right) \pi & -\left(L_{\mathrm{R}}-S\right)\left(1+\varepsilon_{\mathrm{NR}}\right) \rho_{\mathrm{NR}} & -\left(Z_{\mathrm{R}}+L_{\mathrm{R}}\right)\left(1+\varepsilon_{\mathrm{R}}\right) \rho_{\mathrm{R}}
\end{array}\right),
$$

and the driving terms are 


$$
\left(\begin{array}{c}
F_{K} \\
F_{\mathrm{NR}} \\
F_{\mathrm{R}}
\end{array}\right)=\left(\begin{array}{c}
\left(K_{\mathrm{NR}}+L_{K}\right) \rho_{\mathrm{NR}} D_{\mathrm{NR}}+\left(K_{\mathrm{R}}+L_{K}\right) \rho_{\mathrm{R}} D_{\mathrm{R}}+k_{t} \Delta t \\
\left(Z_{\mathrm{NR}}+L_{\mathrm{NR}}\right) \rho_{\mathrm{NR}} D_{\mathrm{NR}}+\left(L_{\mathrm{NR}}-S\right) \rho_{\mathrm{R}} D_{\mathrm{R}}+r_{\mathrm{NR}, t} \Delta t \\
\left(Z_{\mathrm{R}}+L_{\mathrm{R}}\right) \rho_{\mathrm{R}} D_{\mathrm{R}}+\left(L_{\mathrm{R}}-S\right) \rho_{\mathrm{NR}} D_{\mathrm{NR}}+r_{\mathrm{R}, t} \Delta t
\end{array}\right)
$$

In the Appendix, it is shown that this system is stable if the own-response to cost shares exceeds the cross-response. More precisely, there are two conditions. First, the own-response of productivity with respect to cost share - that is, the direct effect of a change in the productivity growth rate of an input with respect to the cost share of that input - must exceed the response to a change in any other cost share. Second, the magnitude of the own-response of the growth rate of the resource-to-capital ratio with respect to a change in the resource cost share must exceed the response to a change in the cost share of the other resource.

Next, we consider the equilibrium itself. At equilibrium, the change in productivity growth rates should be zero, so from equations (40)-(42), the cost shares must satisfy

$$
\left(\begin{array}{ccc}
k_{\pi}+L_{K} & K_{\mathrm{NR}}+L_{K} & K_{\mathrm{R}}+L_{K} \\
K_{\mathrm{NR}}+L_{\mathrm{NR}} & Z_{\mathrm{NR}}+L_{\mathrm{NR}} & L_{\mathrm{NR}}-S \\
K_{\mathrm{R}}+L_{\mathrm{R}} & L_{\mathrm{R}}-S & Z_{\mathrm{R}}+L_{\mathrm{R}}
\end{array}\right)\left(\begin{array}{c}
\Delta \pi_{\mathrm{eqm}} \\
\Delta \rho_{\mathrm{NR}, \mathrm{eqm}} \\
\Delta \rho_{\mathrm{R}, \text { eqm }}
\end{array}\right)=-\left(\begin{array}{c}
k_{t} \Delta t \\
r_{\mathrm{NR}, r} \Delta t \\
r_{\mathrm{R}, r} \Delta t
\end{array}\right) .
$$

If the functional relationships between productivity growth rates and cost shares are stable, so $k_{t}=$ $r_{\mathrm{NR}, t}=r_{\mathrm{R}, t}=0$, then this equation implies constant cost shares, $\Delta \pi_{\mathrm{eqm}}=\Delta \rho_{i, \mathrm{eqm}}=0$, unless the determinant of the matrix is equal to zero. It is straightforward to show that the determinant of this matrix is proportional to the determinant of the matrix $\mathbf{C}$. The stability analysis in the Appendix shows that the determinant is nonzero, so at equilibrium neither the cost shares nor the productivity growth rates are changing. Thus, equilibrium when the relationship between cost shares and productivity growth rates is stable is characterized by Harrod-neutral technical change.

\section{Economic growth with and without resource constraints}

In this section we illustrate the theory developed above by applying it to highly stylized economies. At equilibrium, and with stable relationships between cost shares and productivity growth rates, the resource cost shares are steady. From equation (45), the equilibrium resource productivity growth rate for resource $i$ is

$$
\hat{v}_{i}=\frac{\beta_{i}}{1+\varepsilon_{i}}+\frac{\varepsilon_{i}}{1+\varepsilon_{i}}\left(\hat{Y}-\hat{C}_{i}\right) .
$$

We can also write this in terms of the gap between demand for the resource in the productive sector, $R_{i}$, and the supply, $C_{i}$,

$$
\hat{v}_{i}=\beta_{i}+\varepsilon_{i}\left(\hat{R}_{i}-\hat{C}_{i}\right)
$$

When resources are abundant, so that capacity can keep up with demand, the term in parentheses is negligible, and

$$
\hat{v}_{i} \cong \beta_{i}, \quad \text { abundant resources. }
$$


When resources are scarce, expansion of capacity cannot keep up with demand, and the resource price becomes highly responsive to changes in demand. The elasticity diverges, and

$$
\hat{v}_{i} \cong \hat{Y}-\hat{C}_{i}, \quad \text { scarce resources. }
$$

In the case of scarce resources, resource availability and resource productivity growth become constraints on output. This is better reflected by putting output growth on the left-hand side of the equation,

$$
\hat{Y} \cong \hat{C}_{i}+\hat{v}_{i}, \quad \text { scarce resources. }
$$

The condition of a resource-constrained economy can be put in the context of post-Keynesian theory through a Leontief production function that includes natural resources. In standard post-Keynesian theory, output can be either capital or labor-constrained. With the possibility for limited natural resources, output from the productive sector is,

$$
Y \leq \min \left(\kappa K, \lambda L,\left(1-a_{\mathrm{NR}}\right) v_{\mathrm{NR}} C_{\mathrm{NR}},\left(1-a_{\mathrm{R}}\right) v_{\mathrm{R}} C_{\mathrm{R}}\right) .
$$

We distinguish different types of economy by the factors that constrain them.

\subsection{Agriculturally-based economy}

In an agriculturally-based economy, we assume abundant labor and conventional capital goods (such as plows, hoes, or seed drills). Animal and human power and the productivity of the land are the constraining factors. Resources are renewable, so in this economy,

$$
Y \leq\left(1-a_{\mathrm{R}}\right) v_{\mathrm{R}} C_{\mathrm{R}}
$$

The factor for own-use, $a_{R}$, corresponds to, for example, seed corn in a classical corn model. In the low-productivity, low-input agricultural economies of the ancient Mediterranean, yield was measured by seed harvested to seed sown (Evans 1980). A ratio of 45 was considered a good yield, but in drier areas it could be as low as 4 . A more natural measure when draft animals are used is calories of food energy produced per calorie of work expended, and in traditional subsistence agriculture the ratios could be as low as 2-5 (Evans 1980, 390).

Output in the agriculturally-based economy can be increased by: raising yields (and thereby lowering $a_{\mathrm{R}}$ ), expanding cultivated area (raising $C_{\mathrm{R}}$ ), or by using natural resources more effectively in order to produce a greater abundance or better quality of final goods (raising $v_{R}$ ). Through most of human history since the development of agriculture, yields and final goods production advanced slowly and most increase in output was through extension of the cultivated area. The other factors did nevertheless increase, with development and improvements of plows, seed drills, harnesses, and other agricultural technologies, as well as improvements in the production of non-agricultural goods. Rapid increases were not experienced until the development of high-input agriculture in the $19^{\text {th }}$ century.

King (2015) used energy cost data from Fouquet (2014) and historical estimates of GDP to show that between 1300 and 1800 in the UK, the resource cost share was around 30-40\% of GDP, and GDP grew at about 1\%/year. This fits the path of an agricultural economy outlined above, in that the resource cost share shows no clear trend (while varying considerably around the mean) and growth was modest. 


\subsection{Early industrial revolution}

In the early industrial revolution, from the late $17^{\text {th }}$ century into the $19^{\text {th }}$ century, economies in Europe and the US were mainly agricultural, with small but growing industrial sectors. During the $19^{\text {th }}$ century, the resource cost share fell rapidly in the UK, from $30-40 \%$ to less than $15 \%$ by the first world war (King 2015). After that point the cost share fluctuated, but remained comparatively steady.

The first steam engines burned coal at the minehead to run pumps that drained water out of the mine. Thus, at the expense of a higher own-use of coal (raising $a_{\mathrm{NR}}$ ), a larger amount could be produced (raising $C_{\mathrm{NR}}$ ). The earliest coal-burning steam engines were extremely inefficient, motivating research into improving engine efficiency. In the early phase of the technology, the potential for marginal improvements was large, so the response of non-renewable resource productivity to its cost share was also large. The comparatively mature agricultural sector, by contrast, could only respond slowly until the exploitation of guano as a soil amendment in the mid- $19^{\text {th }}$ century.

The transition from agriculture to industry led to a rapidly falling resource cost share. While this invites a disequilibrium analysis, we can nevertheless represent it in a stylized way using the model developed in the previous section by treating the economies of the early industrial revolution as dual economies, with a large but stagnant agricultural sector and a small but dynamic industrial sector. There was a need for labor in factories, and capital equipment had to be manufactured in increasing quantities, but the main constraint on output was the availability and efficient use of the nonrenewable resource. Under these conditions,

$$
Y_{\text {ind }} \leq\left(1-a_{\mathrm{NR}}\right) v_{\mathrm{NR}} C_{\mathrm{NR}} .
$$

Output growth in the industrial sector was limited by the rate at which resource capacity could be expanded or resource productivity increased. This case corresponds to the conditions in which Jevons wrote The Coal Question. Jevons' main concern was with limited supplies of coal relative to expanding demand and therefore rising prices. Improvements in the efficiency with which coal was used brought increased output, driving demand for goods produced using coal-burning machines.

During the transition, technological innovation, shifting demands for labor, a changing structure of demand, and the introduction of new fuels complicate any explanation of cost shares and productivity growth rates. Nevertheless, it is plausible to propose a composition effect as one factor driving the rapid fall in resource costs as a share of GDP; we explicitly consider a composition effect below when we discuss an economy relying on both renewable and non-renewable resources. For the early industrial economy, as the industrial sector grew in comparison to the agricultural sector, the average resource cost share fell.

\subsection{Non-renewables based industrial economy}

By the $20^{\text {th }}$ century, the non-renewables based industrial economy was well-established in Europe and the UK, and resources were abundant. In such economies, the main constraint is the availability of capital, although prices are affected by periodic shortages of labor. Thus, the standard assumption in post-Keynesian models is capital-constrained output,

$$
Y \leq \kappa K \text {. }
$$


As fossil-dependent technologies matured, the potential to increase productivity shrank, so productivity growth became less responsive to changes in cost shares. Extractive technology had also matured, and while resources were abundant, capacity could expand more or less in line with demand. Under these conditions, the model developed in this paper suggests that cost shares should be steady, while from equation (53), resource productivity growth is driven by shifts in resource prices,

$$
\hat{v}_{\mathrm{NR}}=\beta_{\mathrm{NR}} .
$$

Indeed, energy productivities in the US and UK were comparatively steady (aside from the two world wars), but rose sharply after the oil crises of the 1970s and 1980s.

The direction of causality in the resource abundant case is from economic growth to resource use. This is the causal structure behind the environmental Kuznets curve (EKC) hypothesis. Our basic result is that we should not expect absolute decoupling, with the implication that we should not expect an EKC. Absolute decoupling can be stimulated over the short run if the supply price curve shifts abruptly (or during a structural transition toward sectors with lower resource intensity). However, in either case the fall in resource intensity will not last. When the supply price curve stops shifting, the productivity growth rate falls below the GDP growth rate, while a structural shift will eventually end, leading at best to a sideways-s curve, first rising, then falling, and then rising again. These conclusions appear consistent with the empirical literature, which has found no robust evidence for an EKC (Stern 2004).

\subsection{Industrial economy with renewable and non-renewable resources}

At present, many high- and medium-income economies are supported by a mix of renewable and nonrenewable resources, with non-renewable resources predominating. Unlike the early industrial economies of the $18^{\text {th }}$ and $19^{\text {th }}$ centuries, they are not dual economies: the productive sector might use renewable or non-renewable resources in any combination, with the mix of renewable and nonrenewable resource using capital depending on the cost of the technology.

To discuss the mixed-resource case, we make the simplifying assumption that supply and use of each type of resource can be put in common units, such as exergy (Ayres and Warr 2009). Then total addition of resources, $\Delta R_{\mathrm{tot}}$, can be allocated to resource $i$ in proportion $\theta_{i}$. If additions to resources are in a different proportion to their shares in current consumption, then resource productivities will change through a composition effect, separate from any technological innovation. Such a change appears to be happening in the power generation sector, where renewables have formed the bulk of global investment in new capacity for the past decade, even as they remain a very small share of the total (IEA 2017, 40). Using the formalism of the previous section, we represent this autonomous effect as a shift in the functional relationship between resource productivities and cost shares.

We isolate the autonomous component by writing the change in resource use with the existing composition of resources as

$$
\Delta R_{i}^{\text {const }}=\frac{\Delta Y}{v_{i}} .
$$

We further separate changes in composition from changes in productivity by writing the total change in resources as 


$$
\Delta R_{\mathrm{tot}}^{\mathrm{const}}=\frac{R}{Y} \Delta Y=R \hat{Y}
$$

The autonomous part of the change in resource productivity is then (ignoring second-order terms),

$$
\Delta v_{i}^{\text {aut }}=\frac{Y+\Delta Y}{R_{i}+\theta_{i} \Delta R_{\mathrm{tot}}^{\text {const }}}-\frac{Y+\Delta Y}{R_{i}+\Delta R_{i}^{\text {const }}} \cong \frac{Y}{R_{i}} \frac{\Delta R_{i}^{\text {const }}-\theta_{i} \Delta R_{\mathrm{tot}}^{\text {const }}}{R_{i}}=v_{i}\left(1-\theta_{i} \frac{R_{\mathrm{tot}}}{R_{i}}\right) \hat{Y} .
$$

The ratio of $\theta_{i}$ to $R_{i} / R_{\mathrm{tot}}$ is the degree to which expanded resource demand is supplied by resource $i$ relative to its current contribution. We denote the excess by

$$
x_{i} \equiv \frac{\theta_{i}}{z_{i}}-1, \quad z_{i} \equiv \frac{R_{i}}{R_{\mathrm{tot}}} .
$$

The autonomous contribution to resource productivity growth can then be written

$$
\hat{v}_{i}^{\text {aut }}=-x_{i} \hat{Y}
$$

Assuming relatively steady growth compared to the pace at which the composition of resources is changing, the change in the autonomous contribution to the growth rate is

$$
\Delta \hat{v}_{i}^{\mathrm{aut}}=-\hat{Y} \Delta x_{i}
$$

The cost shares are not constant in this case, because the forcing terms in equation (50) are not zero. We have

$$
\left(\begin{array}{ccc}
k_{\pi}+L_{K} & K_{\mathrm{NR}}+L_{K} & K_{\mathrm{R}}+L_{K} \\
K_{\mathrm{NR}}+L_{\mathrm{NR}} & Z_{\mathrm{NR}}+L_{\mathrm{NR}} & L_{\mathrm{NR}}-S \\
K_{\mathrm{R}}+L_{\mathrm{R}} & L_{\mathrm{R}}-S & Z_{\mathrm{R}}+L_{\mathrm{R}}
\end{array}\right)\left(\begin{array}{c}
\Delta \pi_{\text {eqm }} \\
\Delta \rho_{\mathrm{NR}, \mathrm{eqm}} \\
\Delta \rho_{\mathrm{R}, \mathrm{eqm}}
\end{array}\right)=\left(\begin{array}{c}
0 \\
\hat{Y} \Delta x_{\mathrm{NR}} \\
\hat{Y} \Delta x_{\mathrm{R}}
\end{array}\right)
$$

The equilibrium rate of resource productivity growth is determined by the expressions for the changes in the cost shares, as in equation (45). These can be found by inverting the matrix multiplying the vector of cost shares and applying the inverse to the right-hand side of equation (67). The result can be written as

$$
\begin{gathered}
\Delta \rho_{\mathrm{NR}, \text { eqm }}=\hat{Y}\left(a_{\mathrm{NR}} \Delta x_{\mathrm{NR}}+b_{\mathrm{NR}} \Delta x_{\mathrm{R}}\right), \\
\Delta \rho_{\mathrm{R}, \text { eqm }}=\hat{Y}\left(a_{\mathrm{R}} \Delta x_{\mathrm{R}}+b_{\mathrm{R}} \Delta x_{\mathrm{NR}}\right) .
\end{gathered}
$$

Under the same assumption made in the previous section, that the own-response of intensity with respect to cost shares exceeds the cross-response, the coefficients $a_{\mathrm{NR}}$ and $a_{\mathrm{R}}$ are each positive. The signs of $b_{\mathrm{NR}}$ and $b_{\mathrm{R}}$ are also likely to be positive .

When increasing a resource share from a low base, the value for $\Delta x_{i}$ can be quite large, while it can remain modest for the resource that is being replaced. For example, if renewables account for one

\footnotetext{
${ }^{5}$ The signs depend on the response of resource-to-labor ratios and capital-to-labor ratios. If the responses of these ratios with respect to a change in cost shares have the same sign as the response of resource or capital productivities with respect to a change in cost shares, then the $b_{i}$ are positive.
} 
percent of resource demand, and the share in new investment jumps from one percent to ten percent, then $\Delta x_{\mathrm{R}}$ is equal to nine, while $\Delta x_{\mathrm{NR}}$ is minus one-tenth. The difference in magnitudes can be seen in Figure 3, which shows a hypothetical example in which total resource consumption grows by $2 \%$ per time period, renewables penetration is initially $z_{\mathrm{R}}=1 \%$, and $\theta_{\mathrm{R}}$ gradually rises, to reach a value of one by the $19^{\text {th }}$ time period. It then rises above one, so that on net, non-renewable resources are being withdrawn from the economy.

\section{FIGURE 3 NEAR HERE}

Applying the curves in Figure 3 to equations (68) and (69), in the initial period of rapid introduction of renewables-using capital, both the non-renewable and renewable cost shares are expected to increase, but both later decline.

Productivity growth is being driven continually by the changing composition of capital, so rather than work in equilibrium, we focus on a quasi-equilibrium (an adiabatic approximation). Resource productivity growth is driven by the autonomous shift from equation (65) and the cost-induce response to that change. The quasi-equilibrium values of resource productivity growth are shifted compared to equation (52),

$$
\begin{gathered}
\hat{v}_{\mathrm{NR}}=\beta_{\mathrm{NR}}+\varepsilon_{\mathrm{NR}}\left(\hat{R}_{\mathrm{NR}}-\hat{C}_{\mathrm{NR}}\right)-\hat{Y} x_{\mathrm{NR}}-\frac{\hat{Y}}{1+\varepsilon_{\mathrm{NR}}} \frac{a_{\mathrm{NR}} \Delta x_{\mathrm{NR}}+b_{\mathrm{NR}} \Delta x_{\mathrm{R}}}{\rho_{\mathrm{NR}}}, \\
\hat{v}_{\mathrm{R}}=\beta_{\mathrm{R}}+\varepsilon_{\mathrm{R}}\left(\hat{R}_{\mathrm{R}}-\hat{C}_{\mathrm{R}}\right)-\hat{Y} x_{\mathrm{R}}-\frac{\hat{Y}}{1+\varepsilon_{\mathrm{R}}} \frac{a_{\mathrm{R}} \Delta x_{\mathrm{R}}+b_{\mathrm{R}} \Delta x_{\mathrm{NR}}}{\rho_{\mathrm{R}}} .
\end{gathered}
$$

As indicated, there is both an autonomous and an induced effect on resource productivity growth, in addition to the terms that were already present.

From equations (70) and (71), resource prices, and therefore resource productivities, depend on the pace of demand growth relative to supply capacity. As noted earlier, the main constraint on economic growth in post-Keynesian theory is capital accumulation, with periodic constraints on labor supply. While resources have not historically been constraining, that appears to be changing, resulting in what Galbraith $(2014,108)$ calls the "choke-chain effect". The economy has free rein within the limits placed by resource availability, but is curtailed when it reaches the limits.

\section{Stimulating absolute decoupling}

The central result of this paper is essentially negative: unless resource supply is completely inelastic, we cannot expect sustained absolute decoupling, because the search for profitable innovation does not bring resource productivity growth above the rate of GDP growth. The main novelty of the paper is to show that this result follows from quite general assumptions. While the focus of the paper is a general treatment of decoupling, we demonstrate the model by applying it to a practical question: how to stimulate absolute decoupling through policy. Given the role of cost-share induced technological change in our analysis of decoupling, we focus on price mechanisms.

We consider a policy goal of "dematerializing" non-renewable resources at a rate $m$ in the productive sector, 


$$
\hat{R}_{\mathrm{NR}}=-m \text {. }
$$

From the definition of resource productivity in equation (7) and the expression for the equilibrium growth rate of non-renewable resource productivity in equation (70), this target implies

$$
\hat{Y}+m=\beta_{\mathrm{NR}}+\varepsilon_{\mathrm{NR}}\left(\hat{R}_{\mathrm{NR}}-\hat{C}_{\mathrm{NR}}\right)-\hat{Y} x_{\mathrm{NR}}-\frac{\hat{Y}}{1+\varepsilon_{\mathrm{NR}}} \frac{a_{\mathrm{NR}} \Delta x_{\mathrm{NR}}+b_{\mathrm{NR}} \Delta x_{\mathrm{R}}}{\rho_{\mathrm{NR}}} .
$$

Whether the dematerialization target can in fact be reached depends on the underlying physical processes and the potential to substitute renewable for non-renewable resources. Some materials are very difficult to substitute (Ayres 2007), while today's renewable technologies (such as biofuels) consume non-renewable inputs (such as synthetic fertilizers). Dematerialization then involves questions of substitution (renewable energy sources, bio-based materials) as well as more effective use of the existing inputs.

Technical studies typically show large potential for improving resource efficiency (e.g., for energy: Nadel, Shipley, and Elliott 2004). For the purposes of this paper, we therefore assume that substantial decoupling of fossil fuel use and associated carbon emissions from GDP can occur over a policyrelevant time horizon, but for economic reasons it has not. In this case, equation (73)

Error! Reference source not found.can guide fossil resource pricing policy. It suggests the following mechanisms:

1. Raise the price of non-renewable resources (raise $\beta_{\mathrm{NR}}$ );

2. Constrain exploration or extraction (lower the growth rate of $C_{\mathrm{NR}}$ );

3. Bias new investment towards renewables and away from non-renewables (a negative $x_{\mathrm{NR}}$ ).

None of these mechanisms is new, but the motivation for employing them is. Climate mitigation policy in practice is informed by neoclassical theory, and often includes a carbon price, whether as a tax, the price of an emissions credit in an emissions trading scheme, or an "internal" price used by government or business for planning purposes. Yet, the neoclassical theory of carbon pricing has proven difficult to implement.

The World Bank State and Trends of Carbon Pricing 2016 (World Bank, Ecofys, and Vivid Economics 2016, 56) lists three sources for internal prices: estimates of the social cost of carbon (SCC); estimated marginal abatement cost; or current or anticipated market values of emissions allowances. The first and third approaches should, according to conventional analysis, yield values similar to each other, but the internal prices reported in the World Bank report varied over three orders of magnitude. Experience with SCC estimates (Tol 2011) offers one explanation. The SCC approach is closest in spirit to conventional theory, in that it is an estimate of the marginal cost or benefit that ought to be internalized. However, SCC estimates are challenging (Metcalf 2008); there are substantial uncertainties in the size of some impacts, and when these are taken into account, cost estimates can vary over a wide range (Ackerman and Stanton 2012). Conventional pricing theory faces a further challenge. Each of the three approaches listed above should generate prices that rise over time as greenhouse gas concentrations and global average temperatures rise, yet the European Emissions Trading Scheme (EU ETS) saw prices fall substantially in recent years, part of a longer 
downward trend with large fluctuations around the trend (Meadows, Slingenberg, and Zapfel 2015, fig. 2.5).

Thus, while existing pricing schemes may appear similar to the policy suggested by the theory in this paper, the similarities are superficial. No estimate of social cost or market-clearing price informs equation (73)Error! Reference source not found., and it does not rely on detailed calculation of marginal abatement costs. Rather, a physically-based mitigation goal determines $m$. In practice, countries specify their climate mitigation goals through politically-negotiated and physically-based targets, the nationally determined contributions (NDCs) arising from the Paris climate agreement. While the NDCs are detailed proposals based on technological and cost studies, they are meant to achieve target emissions reductions and therefore find an indirect analogue in the dematerialization target rate $m$.

From equation (73), a carbon price would potentially have three effects. First, if applied at the point of extraction and passed through by firms (as appears to be the case with the EU ETS: see Zachmann and von Hirschhausen 2008), it would make $\beta$ positive, at least for a time. If the price continues to rise, then $\beta$ would remain positive, continually driving (carbon-intensive) non-renewable resource productivity. It would also raise the operating costs of capital that uses non-renewable resources, making renewables-based operations more attractive. This should drive investment in renewablesbased technologies, making $x_{\mathrm{R}}$ positive and $x_{\mathrm{NR}}$ negative. From the (direct) composition effect, this drives non-renewable productivity higher. As firms respond by changing their mix of inputs and prices, there is an indirect effect that tends to offset the direct composition effect. The offsetting indirect effects is expected to be transient, as illustrated schematically in Figure 3. The direct effect will persist as long as the share of renewables-based technology in new investment exceeds its share in installed capital ${ }^{6}$.

\section{Conclusions}

The prospects for sustainability depend crucially on the ability to decouple material throughput from economic value. As this has not happened in the past, one may doubt whether it is possible in the future. To date, the body of theory on the topic has not generated a consensus on mechanisms. In this paper we provide a novel and parsimonious explanation for why decoupling has not yet occurred. The explanation is based on two assumptions: resource prices are responsive to demand and the pace of resource productivity improvement rises with the resource cost share. The mechanism operates within a post-Keynesian theoretical framework in which productive firms can set prices in order to reach a desired rate of return. While the assumptions are not controversial in themselves, they needed some elaboration within the post-Keynesian framework. We proposed a modest extension to postKeynesian theory to better take account of natural resources, and applied a recently-developed theory of cost-share induced technological change that allows for any number of inputs to production (Kemp-Benedict 2017).

The theory presented in this paper demonstrates that when resources are comparatively abundant, relative decoupling may occur, but absolute decoupling will not, except during periods when resource costs are rising faster than GDP (and perhaps during structural transitions). When resources are

\footnotetext{
${ }^{6}$ The author is exploring such a model in separate work.
} 
constrained, GDP growth is determined by the rate of expansion of resource supply and the technically feasible rate of resource productivity growth. In the latter half of the $19^{\text {th }}$ century, when Jevons (1865) wrote The Coal Question, coal was a constraining resource, so any advances in extractive technology or efficiency of use led, paradoxically, to even greater resource use, rather than less.

We may be entering a new resource-constrained era, but even if we are, we are not bringing carbonintensive energy consumption down fast enough to meet globally-agreed carbon mitigation goals (UNEP 2016). The theory presented here suggests that absolute decoupling from a particular natural resource, such as oil, natural gas, or coal, can only be driven by a sufficiently rapidly rising resource price or by ensuring that the share of low-carbon technologies in new investment exceeds its share in the existing capital stock. A policy of a rising carbon price looks superficially like that suggested by conventional theory, which urges that a carbon price be set at a periodically updated social cost of carbon that reflects the (rising) damages inflicted by a marginal unit of carbon emissions. However, the underlying mechanism is quite different, and does not rely on a conceptually and practically challenging estimate of social cost.

\section{References}

Acemoglu, Daron. 1998. "Why Do New Technologies Complement Skills? Directed Technical Change and Wage Inequality.” The Quarterly Journal of Economics 113 (4): 1055-89. https://doi.org/10.1162/003355398555838. . 2002. "Directed Technical Change." The Review of Economic Studies 69 (4): 781-809. https://doi.org/10.1111/1467-937X.00226.

Ackerman, Frank, and Elizabeth A. Stanton. 2012. "Climate Risks and Carbon Prices: Revising the Social Cost of Carbon.” Economics: The Open-Access, Open-Assessment E-Journal 6 (201210): 1. https://doi.org/10.5018/economics-ejournal.ja.2012-10.

Alcott, Blake. 2005. “Jevons' Paradox.” Ecological Economics 54 (1): 9-21. https://doi.org/10.1016/j.ecolecon.2005.03.020.

Auty, Richard. 1985. "Materials Intensity of GDP: Research Issues on the Measurement and Explanation of Change." Resources Policy 11 (4): 275-83. https://doi.org/10.1016/03014207(85)90045-5.

Ayres, Robert U. 2007. "On the Practical Limits to Substitution." Ecological Economics 61 (1): 11528. https://doi.org/10.1016/j.ecolecon.2006.02.011.

Ayres, Robert U., and Jeroen C.J.M. van den Bergh. 2005. "A Theory of Economic Growth with Material/Energy Resources and Dematerialization: Interaction of Three Growth Mechanisms." Ecological Economics 55 (1): 96-118. https://doi.org/10.1016/j.ecolecon.2004.07.023.

Ayres, Robert U., and Benjamin Warr. 2009. The Economic Growth Engine: How Energy and Work Drive Material Prosperity. Cheltenham, UK: Edward Elgar Publishing.

Azevedo, Inês M.L. 2014. "Consumer End-Use Energy Efficiency and Rebound Effects.” Annual Review of Environment and Resources 39 (1): 393-418. https://doi.org/10.1146/annurevenviron-021913-153558. 
Bernardini, Oliviero, and Riccardo Galli. 1993. "Dematerialization: Long-Term Trends in the Intensity of Use of Materials and Energy." Futures 25 (4): 431-48. https://doi.org/10.1016/0016-3287(93)90005-E.

Carter, Colin A. 1999. "Commodity Futures Markets: A Survey." Australian Journal of Agricultural and Resource Economics 43 (2): 209-47. https://doi.org/10.1111/1467-8489.00077.

Cogoy, Mario. 2004. "Dematerialisation, Time Allocation, and the Service Economy." Structural Change and Economic Dynamics 15 (2): 165-81. https://doi.org/10.1016/S0954349X(03)00025-0.

Coutts, Ken, and Neville Norman. 2013. "Post-Keynesian Approaches to Industrial Pricing." In The Oxford Handbook of Post-Keynesian Economics, Volume 1: Theory and Origins, edited by G.C. Harcourt and Peter Kriesler.

Cullenward, Danny, and Jonathan G. Koomey. 2016. "A Critique of Saunders' 'Historical Evidence for Energy Efficiency Rebound in 30 US Sectors." Technological Forecasting and Social Change 103 (February): 203-13. https://doi.org/10.1016/j.techfore.2015.08.007.

Dimitropoulos, John. 2007. "Energy Productivity Improvements and the Rebound Effect: An Overview of the State of Knowledge." Energy Policy 35 (12): 6354-63. https://doi.org/10.1016/j.enpol.2007.07.028.

Dinda, Soumyananda. 2004. "Environmental Kuznets Curve Hypothesis: A Survey." Ecological Economics 49 (4): 431-55. https://doi.org/10.1016/j.ecolecon.2004.02.011.

Duménil, Gérard, and Dominique Lévy. 1995. "A Stochastic Model of Technical Change: An Application to the US Economy (1869-1989)." Metroeconomica 46 (3): 213-245. https://doi.org/10.1111/j.1467-999X.1995.tb00380.x.

Evans, L. T. 1980. “The Natural History of Crop Yield.” American Scientist 68 (4): 388-97. https://doi.org/10.2307/27849950.

Fama, Eugene F., and Kenneth R. French. 1987. "Commodity Futures Prices: Some Evidence on Forecast Power, Premiums, and the Theory of Storage." The Journal of Business 60 (1): 55 73.

Foley, Duncan K. 2003a. Unholy Trinity: Labor, Capital, and Land in the New Economy. London; New York: Routledge.

Foley, Duncan K. 2003b. "Endogenous Technical Change with Externalities in a Classical Growth Model." Journal of Economic Behavior \& Organization 52 (2): 167-89. https://doi.org/10.1016/S0167-2681(03)00020-9.

Fouquet, Roger. 2014. "Long-Run Demand for Energy Services: Income and Price Elasticities over Two Hundred Years." Review of Environmental Economics and Policy 8 (2): 186-207. https://doi.org/10.1093/reep/reu002.

Galbraith, James K. 2014. The End of Normal: The Great Crisis and the Future of Growth. New York, NY, US: Simon \& Schuster.

Gordon, Robert J. 1999. "U.S. Economic Growth since 1870: One Big Wave?” The American Economic Review 89 (2): 123-28. https://doi.org/10.2307/117092.

Gray, Roger W., and David J. S. Rutledge. 1971. "The Economics of Commodity Futures Markets: A Survey." Review of Marketing and Agricultural Economics 39 (4). 
Hall, Charles A. S., Stephen Balogh, and David J.R. Murphy. 2009. "What Is the Minimum EROI That a Sustainable Society Must Have?" Energies 2 (1): 25-47.

https://doi.org/10.3390/en20100025.

Hall, Charles A. S., and Kent A. Klitgaard. 2012. Energy and the Wealth of Nations. New York, NY: Springer New York. https://doi.org/10.1007/978-1-4419-9398-4.

Hicks, J.R. 1932. The Theory of Wages. London: MacMillan and Company Limited.

Higinbotham, Harlow N. 1976. "The Demand for Hedging in the Grain Futures Markets." Ph.D., Chicago, IL, US: University of Chicago.

IEA. 2017. "World Energy Investment 2017.” Paris, France: Organisation for Economic Co-operation and Development. http://www.iea.org/publications/wei2017/.

Jevons, William Stanley. 1865. The Coal Question: An Inquiry Concerning the Progress of the Nation, and the Probable Exhaustion of Our Coal-Mines. London and Cambridge, UK: Macmillan and Co.

Kaldor, Nicholas. 1939. "Speculation and Economic Stability." The Review of Economic Studies 7 (1): 1-27. https://doi.org/10.2307/2967593.

Kalecki, Michal. 1969. Theory of Economic Dynamics: An Essay on Cyclical and Lon-Run Changes in Capitalist Economy. New York, NY, US: Augustus M. Kelly.

Kamara, Avraham. 1982. "Issues in Futures Markets: A Survey." Journal of Futures Markets 2 (3): 261-94. https://doi.org/10.1002/fut.3990020306.

Kemp-Benedict, Eric. 2017. "Biased Technological Change and Kaldor's Stylized Facts.” Working Paper 76803. MPRA Paper. Munich, Germany: Munich Personal RePEc Archive.

Khazzoom, J. Daniel. 1980. "Economic Implications of Mandated Efficiency in Standards for Household Appliances." The Energy Journal 1 (4): 21-40. http://www.jstor.org/stable/41321476.

Kijima, Masaaki, Katsumasa Nishide, and Atsuyuki Ohyama. 2010. "Economic Models for the Environmental Kuznets Curve: A Survey.” Journal of Economic Dynamics and Control 34 (7): 1187-1201. https://doi.org/10.1016/j.jedc.2010.03.010.

King, Carey W. 2015. "Comparing World Economic and Net Energy Metrics, Part 3: Macroeconomic Historical and Future Perspectives.” Energies 8 (11): 12997-20. https://doi.org/10.3390/en81112348.

King, Carey W., John P. Maxwell, and Alyssa Donovan. 2015. "Comparing World Economic and Net Energy Metrics, Part 2: Total Economy Expenditure Perspective.” Energies 8 (11): 12975-96. https://doi.org/10.3390/en81112347.

Kriesler, Peter. 1988. "Kalecki’s Pricing Theory Revisited.” Journal of Post Keynesian Economics 11 (1): 108-30. http://www.jstor.org/stable/4538119.

Kumar, Surender, and Shunsuke Managi. 2009. "Energy Price-Induced and Exogenous Technological Change: Assessing the Economic and Environmental Outcomes." Resource and Energy Economics 31 (4): 334-53. https://doi.org/10.1016/j.reseneeco.2009.05.001.

Lee, Frederic S. 1999. Post Keynesian Price Theory. Cambridge University Press.

McGlade, Christophe, and Paul Ekins. 2015. "The Geographical Distribution of Fossil Fuels Unused When Limiting Global Warming to $2{ }^{\circ} \mathrm{C} . "$ Nature 517 (7533): 187-90. https://doi.org/10.1038/nature14016. 
Meadows, Damien, Yvon Slingenberg, and Peter Zapfel. 2015. "EU ETS: Pricing Carbon to Drive Cost-Effective Reductions across Europe." In EU Climate Policy Explained, edited by Jos Delbeke and Peter Vis, 29-60. London ; New York, NY: Routledge.

Metcalf, Gilbert E. 2008. "Designing a Carbon Tax to Reduce U.S. Greenhouse Gas Emissions." Review of Environmental Economics and Policy, November, ren015. https://doi.org/10.1093/reep/ren015.

Murphy, David J., and Charles A. S. Hall. 2011. "Energy Return on Investment, Peak Oil, and the End of Economic Growth.” Annals of the New York Academy of Sciences 1219 (1): 52-72. https://doi.org/10.1111/j.1749-6632.2010.05940.x.

Nadel, Steven, Anna Shipley, and R. Neal Elliott. 2004. "The Technical, Economic and Achievable Potential for Energy-Efficiency in the US-A Meta-Analysis of Recent Studies." In Proceedings of the 2004 ACEEE Summer Study on Energy Efficiency in Buildings, 8-215.

Nelson, Richard R., and Sidney G. Winter. 1982. An Evolutionary Theory of Economic Change. Cambridge, Mass.: Belknap Press of Harvard University Press.

Perez, Carlota. 2010. "Technological Revolutions and Techno-Economic Paradigms." Cambridge Journal of Economics 34 (1): 185-202. https://doi.org/10.1093/cje/bep051.

Saunders, Harry D. 1992. "The Khazzoom-Brookes Postulate and Neoclassical Growth.” The Energy Journal 13 (4): 131-48. http://www.jstor.org/stable/41322471.

Sorrell, Steve. 2009. “Jevons' Paradox Revisited: The Evidence for Backfire from Improved Energy Efficiency.” Energy Policy 37 (4): 1456-69. https://doi.org/10.1016/j.enpol.2008.12.003.

Stern, David I. 2004. "The Rise and Fall of the Environmental Kuznets Curve." World Development 32 (8): 1419-39. https://doi.org/10.1016/j.worlddev.2004.03.004.

Thomas, Brinda A., and Inês L. Azevedo. 2013. "Estimating Direct and Indirect Rebound Effects for U.S. Households with Input-output Analysis Part 1: Theoretical Framework.” Ecological Economics, Sustainable Urbanisation: A resilient future, 86 (February): 199-210. https://doi.org/10.1016/j.ecolecon.2012.12.003.

Tol, Richard S. J. 2011. "The Social Cost of Carbon.” Annual Review of Resource Economics 3 (1): 419-43. https://doi.org/10.1146/annurev-resource-083110-120028.

UN General Assembly. 2015. "Transforming Our World: The 2030 Agenda for Sustainable Development." Resolution A/RES/70/1. Resolution. United Nations.

UNEP. 2016. The Emissions Gap Report 2016: A UNEP Synthesis Report. Nairobi, Kenya: United Nations Environment Programme.

Wagner, Martin. 2008. "The Carbon Kuznets Curve: A Cloudy Picture Emitted by Bad Econometrics?" Resource and Energy Economics 30 (3): 388-408. https://doi.org/10.1016/j.reseneeco.2007.11.001.

Ward, James D., Paul C. Sutton, Adrian D. Werner, Robert Costanza, Steve H. Mohr, and Craig T. Simmons. 2016. "Is Decoupling GDP Growth from Environmental Impact Possible?" PLOS ONE 11 (10): e0164733. https://doi.org/10.1371/journal.pone.0164733.

Warr, Benjamin, and Robert U. Ayres. 2012. "Useful Work and Information as Drivers of Economic Growth.” Ecological Economics 73 (January): 93-102. https://doi.org/10.1016/j.ecolecon.2011.09.006.

Williams, Jeffrey. 1986. The Economic Function of Futures Markets. Cambridge, UK: Cambride University Press. 
Working, Holbrook. 1948. "Theory of the Inverse Carrying Charge in Futures Markets." Journal of Farm Economics 30 (1): 1-28. https://doi.org/10.2307/1232678.

1949. "The Theory of Price of Storage." The American Economic Review 39 (6): 1254-62. http://www.jstor.org/stable/1816601.

World Bank. 2011. The Changing Wealth of Nations: Measuring Sustainable Development in the New Millennium. Washington, D.C.: World Bank.

World Bank, Ecofys, and Vivid Economics. 2016. "State and Trends of Carbon Pricing 2016." Washington, DC, US: The World Bank. https://openknowledge.worldbank.org/handle/10986/25160.

Zachmann, Georg, and Christian von Hirschhausen. 2008. "First Evidence of Asymmetric Cost Passthrough of EU Emissions Allowances: Examining Wholesale Electricity Prices in Germany." Economics Letters 99 (3): 465-69. https://doi.org/10.1016/j.econlet.2007.09.024. 


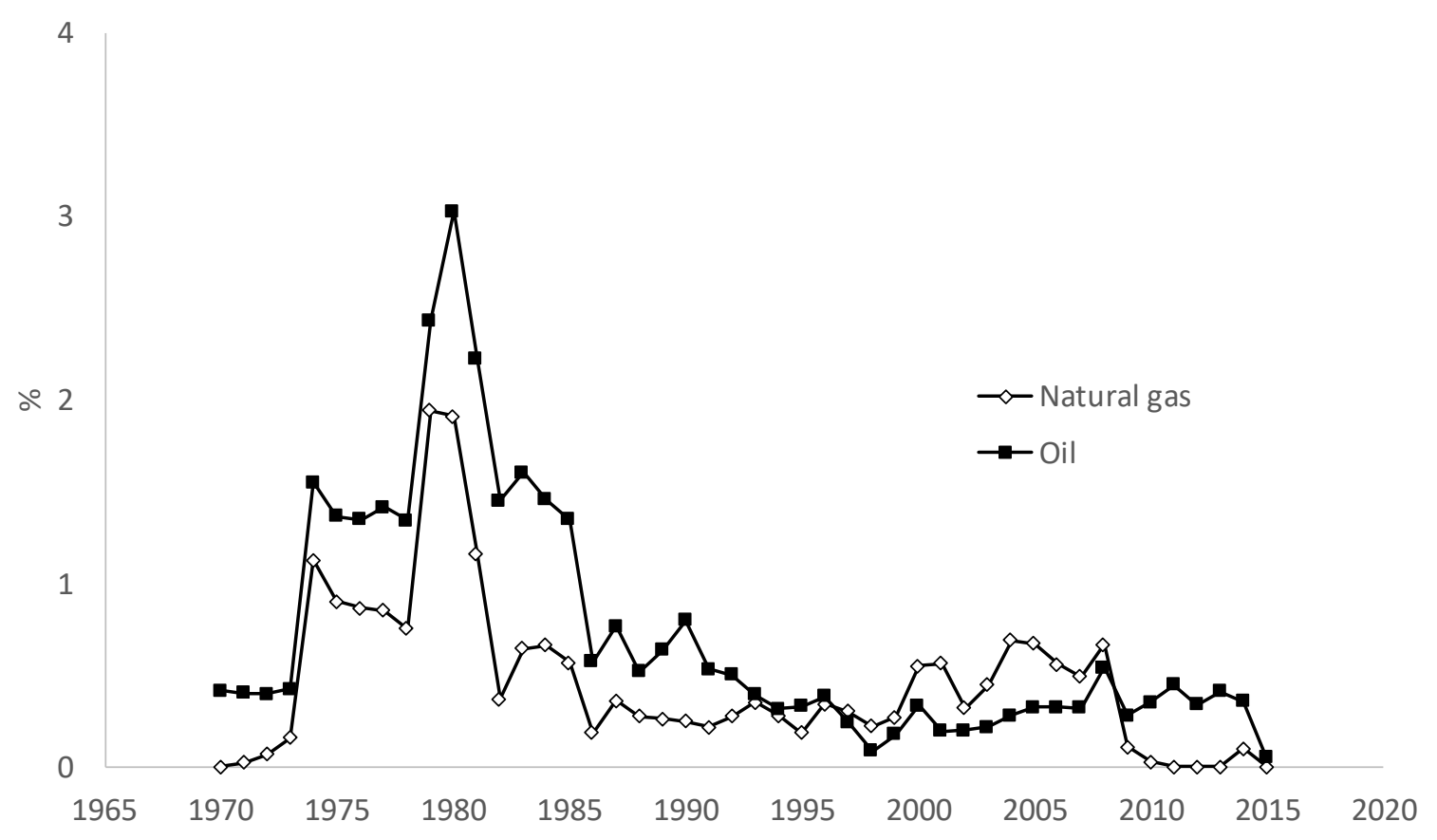

Figure 1: Oil and natural gas rents for the United States (World Bank World Development Indicator database) 


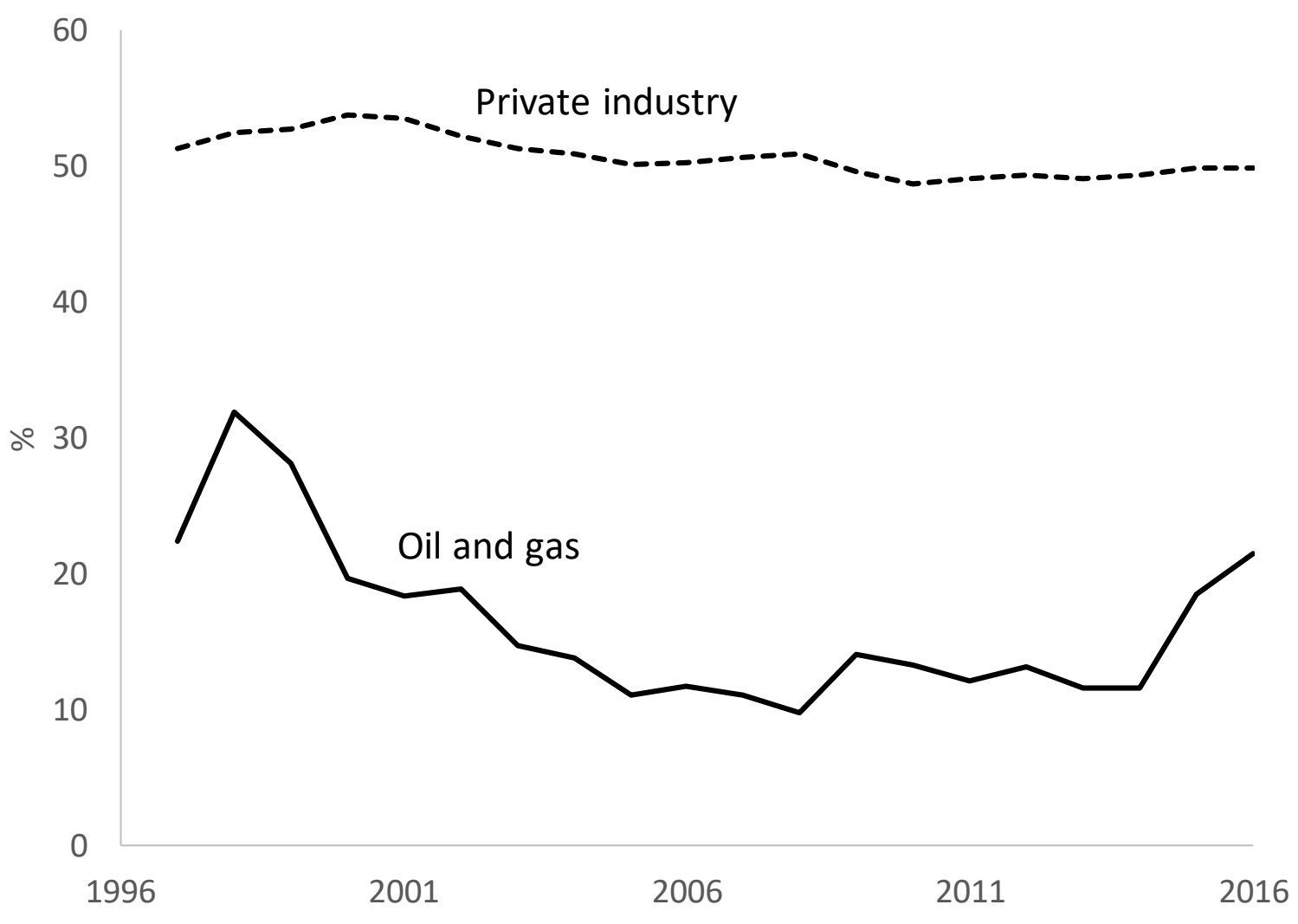

Figure 2: Compensation of employees as a percentage of value added for the US (Bureau of Economic Analysis, "Components of Value Added by Industry as a Percentage of Value Added", accessed 24 November 2017) 


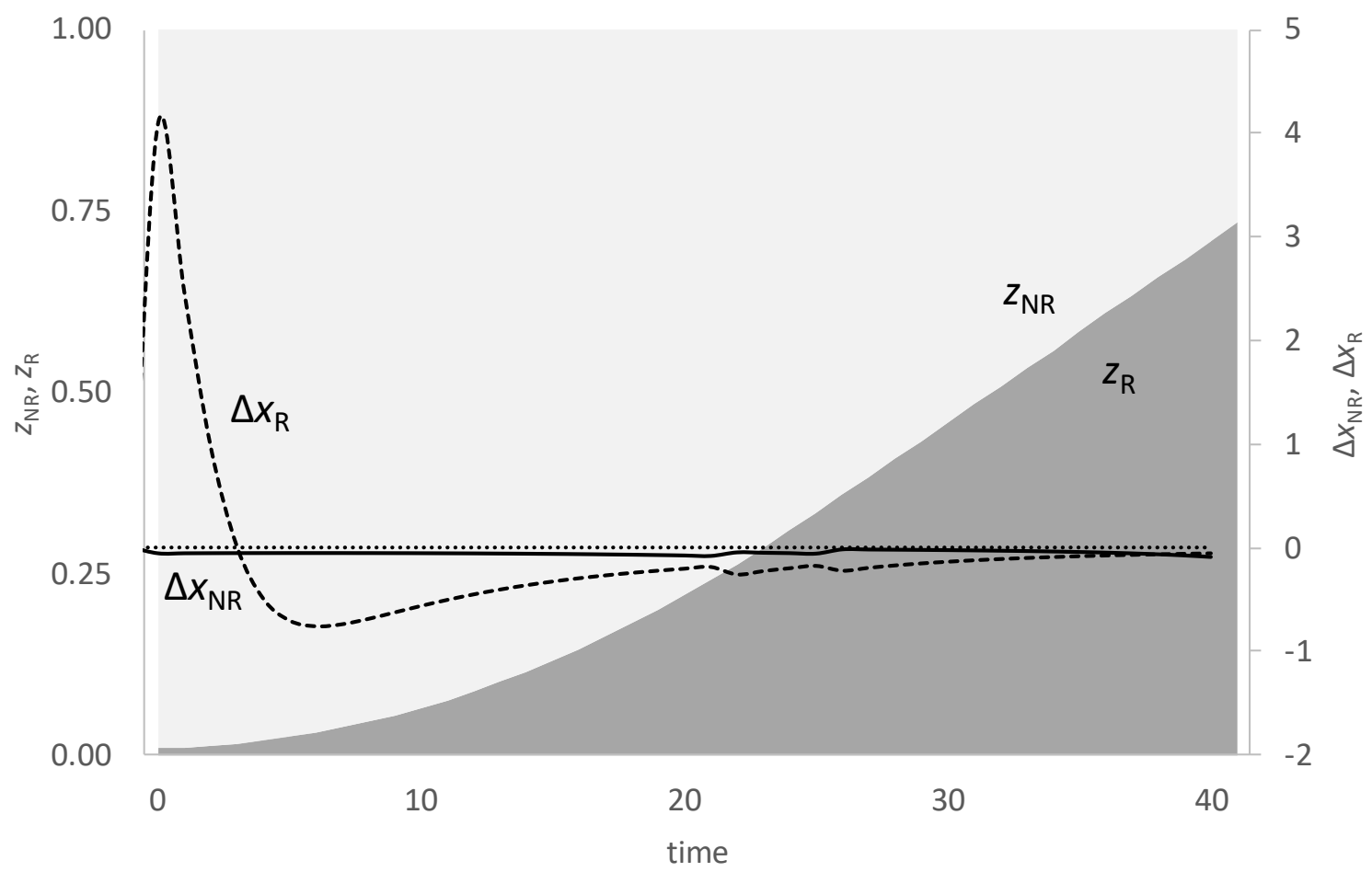

Figure 3: Changes in renewables penetration and autonomous productivity growth factors (the fluctuations arise close to the time when $\theta_{\mathrm{R}}$ reaches its maximum value) 


\section{Appendix}

For any three-by-three Jacobian, stability is determined by the signs of the real parts of the eigenvalues of the matrix. For a general matrix $\mathbf{A}=\left(a_{i j}\right)$, the eigenvalues $\lambda$ satisfy

$$
\left|\begin{array}{ccc}
a_{11}-\lambda & a_{12} & a_{13} \\
a_{21} & a_{22}-\lambda & a_{23} \\
a_{31} & a_{32} & a_{33}-\lambda
\end{array}\right|=0 .
$$

Expanding the determinant gives

$$
-\lambda^{3}+\lambda^{2} T-\lambda\left(M_{1}^{d}+M_{2}^{d}+M_{3}^{d}\right)+D=0,
$$

where $T$ is the trace of $\mathbf{A}, D$ is its determinant, and the $M^{d}{ }_{i}$ are the minors of its diagonal elements. From the Routh-Horwitz stability criterion, we find that $T$ and $D$ must be negative and

$$
M_{1}^{d}+M_{2}^{d}+M_{3}^{d}>\frac{|D|}{|T|} .
$$

To keep the expressions compact, we define

$$
\beta_{\mathrm{R}_{\mathrm{R}}} \equiv\left(1+\varepsilon_{\mathrm{NR}}\right) \rho_{\mathrm{NR}}, \quad \beta_{\mathrm{R}} \equiv\left(1+\varepsilon_{\mathrm{R}}\right) \rho_{\mathrm{R}} .
$$

Then,

$$
\mathbf{C}=\left(\begin{array}{ccc}
-\left(k_{\pi}+L_{K}\right) \pi & -\left(K_{\mathrm{NR}}+L_{K}\right) \beta_{\mathrm{RR}_{\mathrm{R}}} & -\left(K_{\mathrm{R}}+L_{K}\right) \beta_{\mathrm{R}} \\
-\left(K_{\mathrm{NR}}+L_{\mathrm{NR}}\right) \pi & -\left(Z_{\mathrm{NR}}+L_{\mathrm{NR}}\right) \beta_{\mathrm{RR}} & -\left(L_{\mathrm{NR}}-S\right) \beta_{\mathrm{R}} \\
-\left(K_{\mathrm{R}}+L_{\mathrm{R}}\right) \pi & -\left(L_{\mathrm{R}}-S\right) \beta_{\mathrm{RR}} & -\left(Z_{\mathrm{R}}+L_{\mathrm{R}}\right) \beta_{\mathrm{R}}
\end{array}\right) .
$$

Each of the variables that enter this matrix is non-negative, either because of the positive semidefinite nature of the matrix $\mathbf{M}$ or by assumption regarding substitutability and complementarity of inputs. The trace is certainly negative,

$$
T=-\left(k_{\pi}+L_{K}\right) \pi-\left(Z_{\mathrm{NR}}+L_{\mathrm{NR}}\right) \beta_{\mathrm{P}_{\mathrm{R}}}-\left(Z_{\mathrm{R}}+L_{\mathrm{R}}\right) \beta_{\mathrm{R}}<0 .
$$

All terms in the determinant have a common factor. Dividing by that (positive) factor, the determinant is

$$
\begin{aligned}
\frac{D}{\pi \beta_{\mathrm{RR}} \beta_{\mathrm{R}}}= & -\left(k_{\pi}+L_{K}\right)\left[Z_{\mathrm{NR}} Z_{\mathrm{R}}-S^{2}+\left(Z_{\mathrm{NR}}+S\right) L_{\mathrm{R}}+\left(Z_{\mathrm{R}}+S\right) L_{\mathrm{NR}}\right] \\
& +\left(K_{\mathrm{NR}}+L_{K}\right)\left[K_{\mathrm{NR}} Z_{\mathrm{R}}+S K_{\mathrm{R}}+\left(K_{\mathrm{NR}}+S\right) L_{\mathrm{R}}+\left(Z_{\mathrm{R}}-K_{\mathrm{R}}\right) L_{\mathrm{NR}}\right] \\
& +\left(K_{\mathrm{R}}+L_{K}\right)\left[K_{\mathrm{R}} Z_{\mathrm{NR}}+S K_{\mathrm{NR}}+\left(K_{\mathrm{R}}+S\right) L_{\mathrm{NR}}+\left(Z_{\mathrm{NR}}-K_{\mathrm{NR}}\right) L_{\mathrm{R}}\right] .
\end{aligned}
$$

The first term is certainly negative because of a property of positive semi-definite matrices,

$$
Z_{\mathrm{NR}} Z_{\mathrm{R}} \geq S^{2} \text {. }
$$

The other terms are likely to be positive. The question is whether they are large enough in magnitude relative to the first term. We make the simplifying assumption that own-responses dominate 
substitution responses to a change in cost shares. In this case, $K_{\mathrm{NR}}$ and $K_{\mathrm{R}}$ are each less than $k_{\pi}$, so the last two terms are bounded above by $k_{\pi}+L_{K}$ multiplied by the sum of the terms in brackets, which we denote by $\Sigma$,

$$
\Sigma \equiv\left(k_{\pi}+L_{K}\right)\left[\left(Z_{\mathrm{NR}}+S\right)\left(K_{\mathrm{R}}+L_{\mathrm{R}}\right)+\left(Z_{\mathrm{R}}+S\right)\left(K_{\mathrm{NR}}+L_{\mathrm{NR}}\right)\right]
$$

Substituting into equation (A7) and carrying out the sums gives an upper bound on the determinant,

$$
\frac{D}{\pi \beta_{\mathrm{RR}} \beta_{\mathrm{R}}} \leq-\left(k_{\pi}+L_{K}\right)\left[Z_{\mathrm{NR}} Z_{\mathrm{R}}-S^{2}-\left(Z_{\mathrm{NR}}+S\right) K_{\mathrm{R}}-\left(Z_{\mathrm{R}}+S\right) K_{\mathrm{NR}}\right] .
$$

The term in brackets can be factored to give

$$
\frac{D}{\pi \beta_{\mathrm{RR}} \beta_{\mathrm{R}}} \leq-\left(k_{\pi}+L_{K}\right)\left[\left(Z_{\mathrm{NR}}-K_{\mathrm{NR}}\right)\left(Z_{\mathrm{R}}-K_{\mathrm{R}}\right)-\left(-S-K_{\mathrm{NR}}\right)\left(-S-K_{\mathrm{R}}\right)\right] .
$$

From the definitions of the different factors, the expression in brackets can be written

$$
\frac{D}{\pi \beta_{\mathrm{R}} \beta_{\mathrm{R}}} \leq-\left(k_{\pi}+L_{K}\right)\left[\frac{\partial}{\partial \rho_{\mathrm{NR}}} \frac{R_{N R}}{K} \frac{\partial}{\partial \rho_{\mathrm{R}}} \frac{\mathbb{R}_{R}}{K}-\frac{\partial}{\partial \rho_{\mathrm{NR}}} \frac{\mathbb{P}_{R}}{K} \frac{\partial}{\partial \rho_{\mathrm{R}}} \frac{R_{N R}}{K}\right] .
$$

If we assume that the own-response of the growth rate of resource-to-capital ratios with respect to cost shares exceed the cross-response, then the expression in brackets is positive, and the determinant is negative.

Each of the $M_{i}$ is positive,

$$
\begin{gathered}
M_{1}^{d}=\beta_{\mathrm{RR}} \beta_{\mathrm{R}}\left[Z_{\mathrm{NR}} Z_{\mathrm{R}}-S^{2}+\left(Z_{\mathrm{NR}}+S\right) L_{\mathrm{R}}+\left(Z_{\mathrm{R}}+S\right) L_{\mathrm{NR}}\right]>0 . \\
M_{2}^{d}=\pi \beta_{\mathrm{R}}\left[k_{\pi} Z_{\mathrm{R}}-K_{\mathrm{R}}^{2}+L_{\mathrm{R}}\left(k_{\pi}-K_{\mathrm{R}}\right)+L_{K}\left(Z_{\mathrm{R}}-K_{\mathrm{R}}\right)\right]>0 . \\
M_{3}^{d}=\pi \beta_{\mathrm{RR}}\left[k_{\pi} Z_{\mathrm{NR}}-K_{\mathrm{NR}}^{2}+L_{\mathrm{NR}}\left(k_{\pi}-K_{\mathrm{NR}}\right)+L_{K}\left(Z_{\mathrm{NR}}-K_{\mathrm{NR}}\right)\right]>0 .
\end{gathered}
$$

Note that the absolute value of the upper-leftmost entry in the matrix $\mathbf{C}, C_{11}$, multiplied by $M_{1}$, is

$$
\left|C_{11}\right| M_{1}^{d}=\pi \beta_{\mathrm{R}_{\mathrm{R}}} \beta_{\mathrm{R}}\left(k_{\pi}+L_{K}\right)\left[Z_{\mathrm{NR}} Z_{\mathrm{R}}-S^{2}+\left(Z_{\mathrm{NR}}+S\right) L_{\mathrm{R}}+\left(Z_{\mathrm{R}}+S\right) L_{\mathrm{NR}}\right] .
$$

This is the negative of the first term in the determinant. The other two terms are positive, so

$$
\left|C_{11}\right| M_{1}^{d}>|D|
$$

Because each term on the diagonal of $\mathbf{C}$ is negative, we also have

$$
\frac{1}{\left|C_{11}\right|}>\frac{1}{|T|}
$$

Multiplication then gives

$$
M_{1}^{d}+M_{2}^{d}+M_{3}^{d}>M_{1}^{d}>\frac{|D|}{|T|}
$$


The system is thus stable if the own-response of resource productivity and the growth rate of the capital-to-resource ratio exceeds the cross-response. 